\title{
Particle Therapy for Breast Cancer: Benefits and Challenges
}

\author{
Wanrong Luo ${ }^{1 \dagger}$, Yasser F. Ali ${ }^{1,2 \dagger}$, Chong Liu ${ }^{1}$, Yuchen Wang ${ }^{1}$, Caorui Liu ${ }^{1}$, Xiaoni Jin ${ }^{1}$, \\ Guangming Zhou $^{1 *}$ and Ning-Ang Liu ${ }^{1 *}$
}

1 State Key Laboratory of Radiation Medicine and Protection, School of Radiation Medicine and Protection, Collaborative Innovation Center of Radiological Medicine of Jiangsu Higher Education Institutions, Soochow University, Suzhou, China, 2 Biophysics Lab, Physics Department, Faculty of Science, Al-Azhar University, Cairo, Egypt

OPEN ACCESS

Edited by:

Pelagia G. Tsoutsou,

Geneva University Hospitals (HUG),

Switzerland

Reviewed by:

Ulrich W. Langner,

Lifespan, United States

Abraham Kuten,

Israel Cancer Association, Israel

*Correspondence:

Ning-Ang Liu

liuna@suda.edu.cn

Guangming Zhou

gmzhou@suda.edu.cn

${ }^{\dagger}$ These authors have contributed equally to this work

Specialty section:

This article was submitted to Radiation Oncology,

a section of the journal

Frontiers in Oncology

Received: 01 February 2021

Accepted: 07 April 2021

Published: 05 May 2021

Citation:

Luo W, Ali YF, Liu C, Wang Y, Liu C, Jin X, Zhou G and Liu N-A (2021)

Particle Therapy for Breast Cancer:

Benefits and Challenges.

Front. Oncol. 11:662826.

doi: 10.3389/fonc.2021.662826
Hadron therapy with protons and carbon ions is widely attracting interest as a potential competitor of conventional photon radiotherapy. Exquisite dose distribution of charged particles allows for a higher local control of the tumor and lower probability of damage to nearby healthy tissues. Heavy ions have presumed biological advantages rising from their high-linear energy transfer (LET) characteristics, including greater cell-killing effectiveness and reduced heterogeneity dependence of radiation response. Although these advantages are clear and supported by data, only $18.0 \%$ of proton and carbon ion radiotherapy (CIRT) facilities in Europe are treating breast cancers. This review summarizes the physical and radiobiological properties of charged particles, clinical use of particle beam for breast cancer, and suggested approaches to overcome technical and financial challenges.

Keywords: breast cancer, carbon ion radiotherapy, proton therapy, particle therapy, particle treatmentassociated challenges

\section{INTRODUCTION}

Breast cancer, ranking first in incidence and mortality, threatens women's health globally. In the year of 2020 alone, 2.2 million female breast cancer cases were newly diagnosed (1). Surgery represents the mainstay of curative therapy for breast cancer. However, the delivery of adjuvant radiation following lumpectomy has been shown to improve survival and decrease recurrence. A meta-analysis of 10801 breast cancer patients showed that radiotherapy after mass resection can effectively reduce the 10-year recurrence rate and 15-year mortality rate (2). Interest in new radiotherapeutic techniques that minimize deposited doses in proximal normal structures as targets, with the goal of reducing acute and late adverse effects of treatment, has risen in recent years. Particle therapy with protons and heavy ions meets such criteria. The dose deposition of carbon-ion beam, for example, is low in the entrance region where the normal tissue is exposed, but greatly enhanced at the end of their range where the tumor is located, and drops to near zero abruptly thereafter (3). This greater ionizing density within the targeted neoplasm induces a higher degree of irreversible DNA lesions, which overwhelms cancer cells' repair capacity. The relative biologic effectiveness (RBE) concept has been introduced to account for this increased efficiency of cell killing. At clinical institutions, an RBE value of 1.1 to 1.2 has been documented for proton therapy, while for the heavier carbon ions, the RBE distribution in the targeted tissues varies between 2 and 5 (4). The direct-killing effect of heavy ions maintains their ability to kill malignant cells irrespective of 
oxygen concentration. Therefore, even hypoxic tumor tissues are significantly sensitive to carbon ion therapy (5).

Historically, particle facilities are rarely used in the treatment of breast cancer. Just two out of the 11 European centers were treating breast cancer patients. Charged particles has a physical and biological advantage that can be utilized clinically in treating a substantial number of patients with breast cancers in the future.

\section{CLINICAL OUTCOMES FOR PROTON THERAPY}

With the rapid introduction and widespread usage of particle therapy, epidemiologically frequent tumors have been explored. The number of patients treated with proton therapy per year increased from 16,200 in 2015 to approximately 190,000 in 2018 and is expected to grow to be over 300,000 by 2030 (6). In 2014, Bush et al. (7) reported the outcomes of proton therapy (PT) on 100 patients diagnosed with invasive non-lobular carcinoma and a maximal tumor dimension of $3 \mathrm{~cm}$. Postoperative proton beam was given at a dose of 40 Gy in 10 fractions, once daily over 2 weeks. Following treatment, patients underwent a 5-year followup period to monitor toxicity and tumor recurrence. Proton treatment produced excellent ipsilateral breast recurrence-free survival of $97 \%$ and overall survival of $95 \%$ with minimal toxicity. There were no cases of grade 3 or higher acute skin reactions. Furthermore, comparative study has been conducted to estimate the gain obtained with PT in term of recurrence and cardiotoxicity risk using clinical data of EORTC 22922/10925, and NCIC-CTG MA.20, including 41 patients of locally advanced breast cancer with nodal involvement. The median estimated excess of absolute risk of breast cancer recurrence after 10 years was $0.10 \%$ with photons versus $0.02 \%$ with protons (8).

Heart and lungs lie directly underneath the breasts and are likely to receive some radiation too. Total lung doses exceeding 10 Gy has been reported in patients with unilateral mammary carcinoma who received adjuvant RT (9). Women irradiated for left-sided breast cancer receive substantially higher doses to the heart compared to those who irradiated for right-sided breast cancer. Systematic review documented that the average cardiac dose was 5.4 Gy for left-sided breast irradiation compared to a dose of 3.3 Gy in case of right-sided irradiation. Hooning et al. (10), have found an increased development of myocardial infarction and congestive heart failure due to incidental cardiac radiation exposure during internal mammary chain (IMC) treatment. Strikingly, the proton beam significantly lowers mean doses to lung and heart compared to even the most optimized photon beam plan, data are summarized at Table 1, and enables patients to undergo a limited risk of cardiac toxicity (16). Coronary arteries as well are at risk in radiation therapy of breast cancer. A study of 199 patients with breast cancer detected a four to seven-fold increase in incidence of stenosis in mid and distal left anterior descending artery (LAD) artery after RT of left-sided compared to right-sided breast cancer (17).

Patients may be at risk of locoregional recurrence (LRR) after mastectomy due to microscopic residual disease areas in the chest wall and draining lymphatics. Post-mastectomy radiotherapy (PMRT) has been found to reduce LRR risk and potentially improve survival (18). Of note, Protons-PMRT provides excellent locoregional control rates and nearly complete avoidance of cardiopulmonary structures compared to photon-based approaches (19). Additionally, proton fields are delivered en face, allowing for an arms down position (20). Breast reconstruction following a mastectomy has become an integral component of the treatment process for breast cancer. Immediate breast reconstruction undoubtedly maintains body image as well as quality of life, which remains relatively unperturbed, but the opportunities of such an approach must be weighed against potential oncologic and toxicity challenges (21). Smith and colleagues similarly reviewed outcomes of 51 patients who underwent immediate implant reconstruction with adjuvant proton therapy (22). Reconstruction failure occurred in $15 \%$ of patients, raising concerns regarding toxicity with this approach. Thus, patients are often recommended to delay reconstruction.

Re-irradiation (reRT) may be an optimal treatment for recurrent breast cancer, but is challenged by fear of excessive toxicities and inability to safely deliver definitive ( $\geq 60 \mathrm{~Gy}$ ) doses of reRT (21). Based on the favorable physical property of the Bragg peak, proton beam therapy is particularly well suited for reirradiation that has indeed been reported in multiple disease sites, including central nervous system, head and neck,

TABLE 1 | Overview of dose-volume histograms for breast target coverage (PTV) and adjacent critical organs in the proton-photon planning comparison literature.

\begin{tabular}{|c|c|c|c|c|c|c|c|c|c|}
\hline \multirow[t]{3}{*}{ Study } & \multicolumn{3}{|c|}{ PTV } & \multicolumn{6}{|c|}{ OARs } \\
\hline & \multirow[t]{2}{*}{ Photon } & \multirow[t]{2}{*}{ IMRT } & \multirow[t]{2}{*}{ Proton } & \multicolumn{3}{|c|}{ Mean Heart dose } & \multicolumn{3}{|c|}{ Mean dose to Ipsilateral Lung } \\
\hline & & & & Photon & IMRT & Proton & Photon & IMRT & Proton \\
\hline Fogliata et al. (11) & $V_{95 \%}=96.3$ & $V_{95 \%}=94.7$ & $V_{95 \%}=99.8$ & 2.7 Gy & 2.8 Gy & 2.2 Gy & 12.9 Gy & 9.2 Gy & 3.5 Gy \\
\hline Johansson et al. (12) & $V_{95 \%}=93.2$ & $V_{95 \%}=85.9$ & $V_{95 \%}=94$ & 30.5 Gy & 20.5 Gy & 10.5 Gy & 14.5 Gy & 9 Gy & 0.5 Gy \\
\hline Lomax et al. (13) & $V_{95 \%}=86.6$ & $V_{95 \%}=92.2$ & $V_{95 \%}=97.1$ & 15 Gy & 16 Gy & 6 Gy & 17 Gy & 15 Gy & 13 Gy \\
\hline Ares et al.* (14) & $V_{95 \%}=95$ & $V_{95 \%}=99$ & $V_{95 \%}=100$ & 9 Gy & 12 Gy & 1 Gy & $17 \mathrm{~Gy}$ & 15 Gy & 7 Gy \\
\hline Sun et al.* (15) & & $V_{100 \%}=96.9$ & $V_{100 \%}=97.6$ & & 498.4 cGy & 94.6 cGy & & 881.8 cGy & 414.8 cGy \\
\hline
\end{tabular}

PTV, planning target volume; OAR, organ at risk; IMRT, intensity-modulated radiotherapy; $V_{95 \%} V_{100 \%}$, volume that receives at least $95 \%$ and $100 \%$ of the prescribed dose respectively. *reports on sophisticated mode proton beam of variable energy and intensity, IMPT, intensity-modulated proton therapy. 
gastrointestinal, and lung tumors, reviewed at (23). A study of 92 patients with recurrent head and neck cancer showed that reRT with PBT is safe and effective. The treatment was deemed effective since Locoregional failure at 1 year was only $25 \%$, combined with a low risk of late grade 3 or 4 dermatitis and dysphagia ( $8.7 \%$ and $7.1 \%$, respectively) (24). Notably, limited data exist for the use of PBT in the setting of reRT for breast cancer. A multi-institutional report of 50 patients who underwent breast cancer proton re-irradiation showed a favorable local control at a median follow-up of 12.7 months. Of note, the 1-year local recurrence free survival (LFRS) and overall survival (OS) were 93\% and 97\%, respectively, with only $16 \%$ of patients experiencing grade 3 adverse events (25). A recent retrospective analysis of 74 patients treated with PBT for reRT showed a similarly low rate of grade 3 toxicity at any point (13\%) (26), which compared favorably with historical toxicity incidences for photon re-irradiation (27).

\section{CLINICAL OUTCOMES FOR HEAVY ION THERAPY AND NEUTRON RADIATION}

The experience of using carbon ion therapy for breast cancer has been limited, mostly due to the restricted number of qualified facilities and the cost burden of treatment. Nine cases out of a total 11,580 cancer patients were treated with carbon ions at the National Institute of Radiological Sciences (NIRS) between June 1994 and July 2017 in Japan (28). The first published case report of the effectiveness of carbon ions for the treatment of stage I breast cancer without surgery at NIRS was in 2014. Medical examination revealed that the patient had T1N0M0 estrogen receptor-positive invasive ductal carcinomas (24). As a follow-up on this report, Karasawa et al. (29) designed dose escalation study on seven patients with stage I breast cancer, with dose levels of 48.0, 52.8 or 60.0 Gy (RBE), administered in four fractions within 1 week. Three months after radiotherapy, the patients underwent tumor excision for pathological evaluation. Eligibility criteria were being a woman of age 60 years and over, had a life expectancy of over 6 months, had a solitary tumor with a diameter of under $2 \mathrm{~cm}$, and being estrogen receptor (ER) positive and human epidermal growth factor receptor 2 (HER2) negative. Three patients received $48 \mathrm{~Gy}(\mathrm{RBE})$, three received $52.8 \mathrm{~Gy}$ (RBE), and one received 60.0 Gy (RBE). Following irradiation, four patients experienced acute grade 1 skin toxicity, but no other toxicities reported. At 3 months after the carbon ion radiotherapy, most patients had a pathologic response to treatment. At the follow-up of 37-48 months, all patients were alive with no clinical evidence of recurrence or subsequent effects. In a recent analysis of 14 patients who underwent Cion RT for stage I breast cancer, complete tumor disappearance occurred for longer than expected, 2 years after treatment, with only mild adverse events experienced by 10 patients. One recurrence case was noted at 6 months after treatment and the patient eventually died of systematic metastases, while others survived without recurrence and had good cosmetic outcomes at a median follow-up of 5 years (30). Compared to treatment results obtained with radiofrequency ablation (RFA), cryoablation therapy, high-intensity focused ultrasound (HIFU), and stereotactic body radiotherapy (SBRT), C-ion RT is considered to have merits of high tumor control and low adverse events. Harada et al. (31) similarly reported on patients with breast cancer who underwent CIRT at a single dose of 36 Gy. Patients tolerated treatment well and survived more than 8 years without local recurrence, providing additional support of carbon-ion radiotherapy's usefulness and safety.

Besides CIRT, neutron therapy is another appropriate clinical choice for the tumors radioresistant to the conventional photon therapy. Neutron therapy is a type of radiation treatment by using a stream of high-LET subatomic particles with no electric charge, to target and destroy tumor cells. Initial experience with the neutron beam showed a benefit in terms of local control in breast tumor. A prospective randomized study included 29 patients with locally advanced breast cancer (T4, NO-3, MO1), compared to a dose level of 17 with 19 Gy for local control and morbidity. Neutron treatment gave a local control rate of $68 \%$ for the 17 Gy and $83 \%$ for the 19 Gy arm. Following irradiation, few cases of grade 4 skin and subcutaneous necrosis were observed in the 19 Gy arm and none in the 17 Gy (32). A randomly controlled trial on locally advanced breast cancer compared neutron with conventional photon irradiation in terms of tumor control and late radiation morbidity. Although no significant differences were observed between the two treatment groups, neutron therapy improved the quality of life due to its shorter treatment duration (33).

\section{BIOLOGICAL ADVANTAGES OF CHARGED PARTICLES IN BREAST CANCER TREATMENT}

Evidence indicates that breast cancer is composed of phenotypically diverse groups of neoplastic cells, within which there is a small subpopulation termed cancer stem cells (CSCs). CSCs are thought to have the characteristics of self-renewal and therefore play a pivotal role in tumor development, progression, and recurrence after treatment $(34,35)$. Breast cancer cells that have a high expression of CD44 together with low level of CD24 have been reported to have stem cell properties and to have a higher tumorigenic capacity than other cells (36). Clinically, CD44/CD24 expressions are widely used as CSC markers in breast cancer. Around $40 \%$ of all breast malignancy and half of the locally advanced breast cancers contain regions of intratumoral hypoxia with an oxygen concentration below that of normal mammary tissue $(37,38)$, perhaps through promoting CSC maintenance (39) that consequently makes tumors radioand chemo-resistant. A preliminary study indicates an increased effectiveness of low-energy protons in eliminating CSCs from mammary human cancer cells in vitro (40). Intriguingly, it showed a greater capability of eliminating CSCs than photonbased therapy at the same dose (41), therefore, it has substantial clinical advantages on mammary tumors with hypoxic fractions. Such better performance is explained by differences in induction 
and repair of DNA damage. Held et al., observed more unrepaired clustered DNA lesions after carbon-ion irradiation, while almost all sporadic DNA damage sites were efficiently rejoined after the same dose of X-rays treatment (42).

Increasing evidence reveals that mutations in the tumor suppressor p53 gene are the most common, occurring in over $50 \%$ of human cancers. Tumors with p 53 mutation(s) are more resistant to radiotherapy by abolishing the p53 dependent apoptosis in response to radiation exposure (43-45). In breast cancers, p53 is mutated in almost $30 \%$ of clinical cases and found associated with an elevated risk of mortality (2.27-fold) compared with patients with no such mutation $(46,47)$. Compared with conventional X-ray treatment, carbon ions showed the advantage of overcoming radioresistance; it effectively induces p53-independent apoptosis (48) via E2F1 signal pathway (49). Upregulation of E2F1 protein expression caused a higher reduction in clonogenic survival, G2/M phase arrest, promotion of apoptosis rate, up-regulation of phosphor$\mathrm{Rb}, \mathrm{Bax}$, and cleaved-caspase 3 proteins expressions without $\mathrm{p} 53$.

\section{COMBINATION STRATEGIES TO IMPROVE CHARGED PARTICLE TREATMENT EFFICACY}

Even though local control is generally very high with particle therapy, combination of systemic therapies and irradiation become the recommended treatment option for most malignancies to control metastasis and increase survival (50). In vitro experiments on breast cancer cells provided useful indications on the combination of different antineoplastic agents with CIRT. Combination therapy resulted in greater cytotoxicity toward human mammary epithelial cancer line MCF7 and showed promise in facilitating the delivery of antitumor drugs (51). Few preclinical studies have been published to investigate the underlying mechanism and efficacy of carbon ion radiation in combination with immunotherapy (IT) (52). Carbon-ion irradiation resulted in tumor elimination, rejection of secondary tumor inoculation, and T-cell activation. These antitumor effects were enhanced by the combination of dendritic cells (DCs) as IT. Indeed, more preclinical research containing large-sized samples, diverse immunotherapies, various radiation doses, and fractionations needs to be done before CIRT achieves its promise.

Another treatment combination is CIRT and chemotherapy which has shown great outcomes in preclinical studies for cancer cures (53). Combined protocol efficiently kills triple-negative breast cancer (TNBC) stem cells in vitro, likely due to suppressed colony formation, inhibited cell cycles, irreparable DNA lesions, and enhanced apoptosis compared to X-ray combined with cisplatin or carbon ion beam alone.

Co-treatment with PU-H7, a Hsp90 Inhibitor, sensitizes human cancer cells to carbon-ion irradiation by inhibiting homologous recombination (HR) and non-homologous end joining (NHEJ) DSB repair pathways. While the radiosensitization effect of PU-H71 was not observed in human normal cell lines (54).
This selective effect illustrated an impressive and encouraging outcome for future protocols combining particle therapy and Hsp90 inhibitors.

\section{CURRENT ISSUES WITH THE USE OF PARTICLE THERAPY}

Breast cancer poses a challenging problem in accurate dose calculation due to respiratory-induced motion. Motioninduced uncertainty compromises CT geometrical information of the target and nearby normal organs as the CT reconstruction algorithm was developed for static objects (6). Respiratory Gating and Breath hold techniques including breath-hold-atinhalation (BHI), and breath-hold-at-exhalation (BHE) are various anatomic motion management strategies, currently in use to mitigate the effects of thr breathing motion. A clinical practice shows that significantly low doses to organs at risk are observed in an enhanced end-inspiration phase and the risk of cardiopulmonary complications was $1 \%$ or less (55). In contrast, Breast radiotherapy with scanned proton beams results in better dose coverage of regional lymph node targets and lower doses delivered to critical structures irrespective of whether respiratory gating is used or not (56). Indeed, Proton spot scanning seems to maintain a low cardiovascular burden beyond what could be achieved with enhanced inspiration gating and photon therapy (57).

Cost is the main barrier for the diffusion of particle therapy service; most of the expense being for the construction of accelerating structure and rotating gantries to focus the beam down to the patient. Proton gantry size is still a limiting factor; most gantries have diameters of several meters, owing to magnet coils required to bend the beam path. However, Superconducting magnets reduced gantry size and weight to practical proportions and decreased the demands on the mechanical structure (58). Further technological efforts based on robotic applications are made up in order to resolve cost barriers. Briefly, fixed-beam treatment rooms, where the patient is rotated and translated in space with a robotic arm solution to enable beam incidence from various angles for optimal target coverage (59). Nevertheless, gantry replacement by one or a few fixed beams has been argued to result in sub-optimal treatments in a significant proportion of cases (60) but this depends on the kind of technology adopted for positioning.

\section{CONCLUSION}

The ballistic and radiobiological properties of particle beam make it a potential treatment option for radioresistant breast cancer subtypes. it could be more cost efficient than photons in patients who are at risk of cardiovascular disease. Further development on motion mitigation strategies and tracking algorithms are required to minimize range uncertainties that ultimately help to translate the dosimetric advantages to clinical benefit. 


\section{AUTHOR CONTRIBUTIONS}

WL and YA drafted the paper. N-AL and GZ developed the final version. $\mathrm{CL}, \mathrm{YW}, \mathrm{CRL}$ and $\mathrm{XJ}$ contributed to writing and to the critical review of the manuscript. All authors contributed to the article and approved the submitted version.

\section{FUNDING}

This work was supported by the Suzhou Science and Technology Development Project (SYS2020090), the Program of the Network-

\section{REFERENCES}

1. Sung H, Ferlay J, Siegel RL, Laversanne M, Soerjomataram I, Jemal A, et al. Global Cancer Statistics 2020: GLOBOCAN Estimates of Incidence and Mortality Worldwide for 36 Cancers in 185 Countries. CA Cancer J Clin (2021). doi: 10.3322/caac.21660

2. Fisher B, Anderson S, Bryant J, Margolese RG, Deutsch M, Fisher ER, et al. Twenty-Year Follow-Up of a Randomized Trial Comparing Total Mastectomy, Lumpectomy, and Lumpectomy Plus Irradiation for the Treatment of Invasive Breast Cancer. N Engl J Med (2002) 347(16):123341. doi: 10.1056/NEJMoa022152

3. Newhauser WD, Durante M. Assessing the Risk of Second Malignancies After Modern Radiotherapy. Nat Rev Cancer (2011) 11(6):438-48. doi: 10.1038/ nrc3069

4. Choi J, Kang JO. Basics of Particle Therapy II: Relative Biological Effectiveness. Radiat Oncol J (2012) 30(1):1-13. doi: 10.3857/roj.2012.30.1.1

5. Allen C, Borak TB, Tsujii H, Nickoloff JA. Heavy Charged Particle Radiobiology: Using Enhanced Biological Effectiveness and Improved Beam Focusing to Advance Cancer Therapy. Mutat Res (2011) 711(1-2):150-7. doi: 10.1016/j.mrfmmm.2011.02.012

6. Han Y. Current Status of Proton Therapy Techniques for Lung Cancer. Radiat Oncol J (2019) 37(4):232-48. doi: 10.3857/roj.2019.00633

7. Bush DA, Do S, Lum S, Garberoglio C, Mirshahidi H, Patyal B, et al. Partial Breast Radiation Therapy With Proton Beam: 5-Year Results With Cosmetic Outcomes. Int J Radiat Oncol Biol Phys (2014) 90(3):501-5. doi: 10.1016/ j.ijrobp.2014.05.1308

8. Stick LB, Yu J, Maraldo MV, Aznar MC, Pedersen AN, Bentzen SM, et al. Joint Estimation of Cardiac Toxicity and Recurrence Risks After Comprehensive Nodal Photon Versus Proton Therapy for Breast Cancer. Int J Radiat Oncol Biol Phys (2017) 97(4):754-61. doi: 10.1016/ j.ijrobp.2016.12.008

9. Vasiljevic D, Arnold C, Neuman D, Fink K, Popovscaia M, Kvitsaridze I, et al. Occurrence of Pneumonitis Following Radiotherapy of Breast Cancer - A Prospective Study. Strahlenther Onkol (2018) 194(6):520-32. doi: 10.1007/ s00066-017-1257-z

10. Hooning MJ, Botma A, Aleman BMP, Baaijens MHA, Bartelink H, Klijn JGM, et al. Long-Term Risk of Cardiovascular Disease in 10-Year Survivors of Breast Cancer. J Natl Cancer Inst (2007) 99(5):365-75. doi: 10.1093/jnci/ djk064

11. Fogliata A, Bolsi A, Cozzi L. Critical Appraisal of Treatment Techniques Based on Conventional Photon Beams, Intensity Modulated Photon Beams and Proton Beams for Therapy of Intact Breast. Radiother Oncol (2002) 62 (2):137-45. doi: 10.1016/S0167-8140(01)00476-5

12. Johansson J, Isacsson U, Lindman H, Montelius A, Glimelius B. Node-Positive Left-Sided Breast Cancer Patients After Breast-Conserving Surgery: Potential Outcomes of Radiotherapy Modalities and Techniques. Radiother Oncol (2002) 65(2):89-98. doi: 10.1016/S0167-8140(02)00266-9

13. Lomax AJ, Cella L, Weber D, Kurtz JM, Miralbell R. Potential Role of Intensity-Modulated Photons and Protons in the Treatment of the Breast type Joint Usage/Research Center for Radiation Disaster Medical Science, the Collaborative Innovation Center of Radiological Medicine of Jiangsu Higher Education Institutions, and a project funded by the Priority Academic Program Development of Jiangsu Higher Education Institutions (PAPD).

\section{ACKNOWLEDGMENTS}

The authors would like to thank Professor Jian Tong, School of Public Health, Medical College of Soochow University, Suzhou for his constructive suggestions when preparing this publication.

and Regional Nodes. Int J Radiat Oncol Biol Phys (2003) 55(3):785-92. doi: 10.1016/S0360-3016(02)04210-4

14. Ares C, Khan S, Macartain AM, Heuberger J, Goitein G, Gruber G, et al. Postoperative Proton Radiotherapy for Localized and Locoregional Breast Cancer: Potential for Clinically Relevant Improvements? Int J Radiat Oncol Biol Phys (2010) 76(3):685-97. doi: 10.1016/j.ijrobp.2009.02.062

15. Sun T, Lin X, Tong Y, Liu X, Pan L, Tao C, et al. Heart and Cardiac Substructure Dose Sparing in Synchronous Bilateral Breast Radiotherapy: A Dosimetric Study of Proton and Photon Radiation Therapy. Front Oncol (2019) 9:1456. doi: 10.3389/fonc.2019.01456

16. Taylor CW, Wang Z, Macaulay E, Jagsi R, Duane F, Darby SC, et al. Exposure of the Heart in Breast Cancer Radiation Therapy: A Systematic Review of Heart Doses Published During 2003 to 2013. Int J Radiat Oncol Biol Phys (2015) 93(4):845-53. doi: 10.1016/j.ijrobp.2015.07.2292

17. Nilsson G, Holmberg L, Garmo H, Duvernoy O, Sjögren I, Lagerqvist B, et al. Distribution of Coronary Artery Stenosis After Radiation for Breast Cancer. J Clin Oncol (2012) 30(4):380-6. doi: 10.1200/JCO.2011.34.5900

18. Torres MA, Horst KC, Freedman GM. Postmastectomy and Regional Nodal Radiation for Breast Cancer. J Clin Oncol (2020) 38(20):2299-309. doi: 10.1200/JCO.19.02908

19. MacDonald SM, Patel SA, Hickey S, Specht M, Isakoff SJ, Gadd M, et al. Proton Therapy for Breast Cancer After Mastectomy: Early Outcomes of a Prospective Clinical Trial. Int J Radiat Oncol Biol Phys (2013) 86(3):484-90. doi: 10.1016/j.ijrobp.2013.01.038

20. Depauw N, Batin E, Johnson A, MacDonald SM, Jimenez RB. Arms Positioning in Post-Mastectomy Proton Radiation: Feasibility and Development of a New Arms Down Contouring Atlas. Phys Imaging Radiat Oncol (2020) 14:6-11. doi: 10.1016/j.phro.2020.04.003

21. Motwani SB, Strom EA, Schechter NR, Butler CE, Lee GK, Langstein HN, et al. The Impact of Immediate Breast Reconstruction on the Technical Delivery of Postmastectomy Radiotherapy. Int J Radiat Oncol Biol Phys (2006) 66(1):76-82. doi: 10.1016/j.ijrobp.2006.03.040

22. Smith NL, Jethwa KR, Viehman JK, Harmsen WS, Gonuguntla K, Elswick SM, et al. Post-Mastectomy Intensity Modulated Proton Therapy After Immediate Breast Reconstruction: Initial Report of Reconstruction Outcomes and Predictors of Complications. Radiother Oncol (2019) 140:76-83. doi: 10.1016/j.radonc.2019.05.022

23. Verma V, Rwigema JCM, Malyapa RS, Regine WF, Simone CB II. Systematic Assessment of Clinical Outcomes and Toxicities of Proton Radiotherapy for Reirradiation. Radiother Oncol (2017) 125(1):21-30. doi: 10.1016/ j.radonc.2017.08.005

24. Romesser PB, Cahlon O, Scher ED, Hug EB, Sine K, DeSelm C, et al. Proton Beam Reirradiation for Recurrent Head and Neck Cancer: Multi-institutional Report on Feasibility and Early Outcomes. Int J Radiat Oncol Biol Phys (2016) 95(1):386-95. doi: 10.1016/j.ijrobp.2016.02.036

25. Thorpe CS, Niska JR, Girardo ME, Kosiorek HE, McGee LA, Hartsell WF, et al. Proton Beam Therapy Reirradiation for Breast Cancer: Multiinstitutional Prospective PCG Registry Analysis. Breast J (2019) 25(6):116070. doi: $10.1111 /$ tbj. 13423 
26. Fattahi S, Ahmed SK, Park SS, Petersen IA, Shumway DA, Stish BJ, et al. Reirradiation for Locoregional Recurrent Breast Cancer. Adv Radiat Oncol (2021) 6(1). doi: 10.1016/j.adro.2020.100640

27. Oldenborg S, Griesdoorn V, Rv Os, Kusumanto YH, Oei BS, Venselaar JL, et al. Reirradiation and Hyperthermia for Irresectable Locoregional Recurrent Breast Cancer in Previously Irradiated Area: Size Matters. Radiother Oncol (2015) 117(2):223-8. doi: 10.1016/j.radonc.2015.10.017

28. Mohan R, Held KD, Story MD, Grosshans D, Capala J. Proceedings of the National Cancer Institute Workshop on Charged Particle Radiobiology. Int $J$ Radiat Oncol Biol Phys (2018) 100(4):816-31. doi: 10.1016/ j.ijrobp.2017.12.260

29. Karasawa K, Omatsu T, Arakawa A, Yamamoto N, Ishikawa T, Saito M, et al. A Phase I Clinical Trial of Carbon Ion Radiotherapy for Stage I Breast Cancer: Clinical and Pathological Evaluation. J Radiat Res (2019) 60(3):342-7. doi: 10.1093/jrr/rry113

30. Karasawa K, Omatsu T, Shiba S, Irie D, Wakatsuki M, Fukuda S. A Clinical Study of Curative Partial Breast Irradiation for Stage I Breast Cancer Using Carbon Ion Radiotherapy. Radiat Oncol (2020) 15(1):265. doi: 10.1186/ s13014-020-01713-1

31. Harada M, Karasawa K, Yasuda S, Kamada T, Nemoto K. One Shot of Carbon-Ion Radiotherapy Cured a 6-cm Chemo-Resistant Metastatic Liver Tumor: A Case of Breast Cancer. Jpn J Radiol (2015) 33(9):598-602. doi: 10.1007/s11604-015-0462-x

32. Stannard CE, Vernimmen FJ, Jones DT, Wijk ALV, Brennan SM, Visser AM, et al. The Neutron Therapy Clinical Programme At the National Accelerator Centre (NAC). Bull Cancer Radiother (1996) 83 Suppl:87s-92s. doi: 10.1016/ 0924-4212(96)84890-0

33. Murray EM, Werner ID, Schmitt G, Stannard C, Gudgeon A, Wilson J, et al. Neutron Versus Photon Radiotherapy for Local Control in Inoperable Breast Cancer. Strahlenther Onkol (2005) 181(2):77-81. doi: 10.1007/s00066-0051298-6

34. Camerlingo R, Ferraro GA, Francesco FD, Romano M, Nicoletti G, Bonito $\mathrm{MD}$, et al. The Role of CD44+/CD24-/low Biomarker for Screening, Diagnosis and Monitoring of Breast Cancer. Oncol Rep (2014) 31(3):1127-32. doi: 10.3892/or.2013.2943

35. Phillips TM, McBride WH, Pajonk F. The Response of CD24(-/low)/CD44+ Breast Cancer-Initiating Cells to Radiation. J Natl Cancer Inst (2006) 98 (24):1777-85. doi: 10.1093/jnci/djj495

36. Al-Hajj M, Wicha MS, Benito-Hernandez A, Morrison SJ, Clarke MF. Prospective Identification of Tumorigenic Breast Cancer Cells. Proc Natl Acad Sci (2003) 100(7):3983-8. doi: 10.1073/pnas.0530291100

37. Williams KJ, Cowen RL, Stratford IJ. Hypoxia and Oxidative Stress in Breast Cancer Tumour Hypoxia - Therapeutic Considerations. Breast Cancer Res (2001) 3(5):328. doi: 10.1186/bcr316

38. Hamdan FH, Zihlif MA. Gene Expression Alterations in Chronic Hypoxic MCF7 Breast Cancer Cell Line. Genomics (2014) 104(6, Part B):477-81. doi: 10.1016/j.ygeno.2014.10.010

39. Visvader JE, Lindeman GJ. Cancer Stem Cells in Solid Tumours: Accumulating Evidence and Unresolved Questions. Nat Rev Cancer (2008) 8(10):755-68. doi: 10.1038/nrc2499

40. Fu Q, Quan Y, Wang W, Mei T, Wu J, Li J, et al. Response of Cancer StemLike Cells and non-Stem Cancer Cells to Proton and $\gamma$-Ray Irradiation. Nucl Instrum Methods Phys Res B (2012) 286:346-50. doi: 10.1016/ j.nimb.2012.01.032

41. Quan Y, Wang W, Fu Q, Mei T, Wu J, Li J, et al. Accumulation Efficiency of Cancer Stem-Like Cells Post $\gamma$-Ray and Proton Irradiation. Nucl Instrum Methods Phys Res B (2012) 286:341-5. doi: 10.1016/j.nimb.2011.11.019

42. Held KD, Kawamura H, Kaminuma T, Paz AES, Yoshida Y, Liu Q, et al. Effects of Charged Particles on Human Tumor Cells. Front Oncol (2016) 6 (23). doi: 10.3389 /fonc.2016.00023

43. Lee JM, Bernstein A. p53 Mutations Increase Resistance to Ionizing Radiation. Proc Natl Acad Sci U S A (1993) 90(12):5742-6. doi: 10.1073/pnas.90.12.5742

44. Bergh J. Clinical Studies of p53 in Treatment and Benefit of Breast Cancer Patients. Endocr Relat Cancer (1999) 6(1):51-9. doi: 10.1677/erc.0.0060051

45. Tchelebi L, Ashamalla H, Graves PR. Mutant p53 and the Response to Chemotherapy and Radiation. In: SP Deb, S Deb, editors. Mutant $p 53$ and
MDM2 in Cancer. Dordrecht: Springer Netherlands (2014). p. 133-59. doi: 10.1007/978-94-017-9211-0_8

46. Varna M, Bousquet G, Plassa L-F, Bertheau P, Janin A. TP53 Status and Response to Treatment in Breast Cancers. J BioMed Biotechnol (2011) 2011:284584. doi: 10.1155/2011/284584

47. Huszno J, Grzybowska E. TP53 Mutations and SNPs as Prognostic and Predictive Factors in Patients With Breast Cancer. Oncol Lett (2018) 16 (1):34-40. doi: 10.3892/ol.2018.8627

48. Mori E, Takahashi A, Yamakawa N, Kirita T, Ohnishi T. High LET Heavy Ion Radiation Induces p53-independent Apoptosis. J Radiat Res (2009) 50(1):3742. doi: 10.1269 /jrr.08075

49. Xie Y, Si J, Wang Y-P, Li H-Y, Di C-X, Yan J-F, et al. E2F is Involved in Radioresistance of Carbon Ion Induced Apoptosis Via Bax/caspase 3 Signal Pathway in Human Hepatoma Cell. J Cell Physiol (2018) 233(2):1312-20. doi: $10.1002 /$ jcp. 26005

50. Loeffler JS, Durante M. Charged Particle Therapy-Optimization, Challenges and Future Directions. Nat Rev Clin Oncol (2013) 10(7):411-24. doi: 10.1038/ nrclinonc.2013.79

51. Zhou C, Rong Y, Konishi T, Xiang Z, Zihui F, Hong M. Effect of Carbon-Ion Radiation on Drug Transporters Organic Anion Transporting Polypeptides in Breast Cancer Cells. Radiat Res (2017) 187(6):689-700. doi: 10.1667/ RR14603.1

52. Matsunaga A, Ueda Y, Yamada S, Harada Y, Shimada H, Hasegawa M, et al. Carbon-Ion Beam Treatment Induces Systemic Antitumor Immunity Against Murine Squamous Cell Carcinoma. Cancer (2010) 116(15):3740-8. doi: $10.1002 /$ cncr. 25134

53. Sai S, Vares G, Kim EH, Karasawa K, Wang B, Nenoi M, et al. Carbon Ion Beam Combined With Cisplatin Effectively Disrupts Triple Negative Breast Cancer Stem-Like Cells In Vitro. Mol Cancer (2015) 14:166. doi: 10.1186/ s12943-015-0429-7

54. Lee Y, Li HK, Masaoka A, Sunada S, Hirakawa H, Fujimori A, et al. The Purine Scaffold Hsp90 Inhibitor PU-H71 Sensitizes Cancer Cells to Heavy Ion Radiation by Inhibiting DNA Repair by Homologous Recombination and non-Homologous End Joining. Radiother Oncol (2016) 121(1):162-8. doi: 10.1016/j.radonc.2016.08.029

55. Korreman SS, Pedersen AN, Josipović M, Aarup LR, Juhler-Nøttrup T, Specht L, et al. Cardiac and Pulmonary Complication Probabilities for Breast Cancer Patients After Routine End-Inspiration Gated Radiotherapy. Radiother Oncol (2006) 80(2):257-62. doi: 10.1016/j.radonc.2006.07.020

56. Dasu A, Flejmer AM, Edvardsson A, Nyström PW. Normal Tissue Sparing Potential of Scanned Proton Beams With and Without Respiratory Gating for the Treatment of Internal Mammary Nodes in Breast Cancer Radiotherapy. Phys Med (2018) 52:81-5. doi: 10.1016/j.ejmp.2018.06.639

57. Flejmer AM, Edvardsson A, Dohlmar F, Josefsson D, Nilsson M, Nyström PW, et al. Respiratory Gating for Proton Beam Scanning Versus Photon 3DCRT for Breast Cancer Radiotherapy. Acta Oncol (2016) 55(5):577-83. doi: 10.3109/0284186X.2015.1120883

58. Paganetti H. Proton Beam Therapy. In: H Paganetti, editor. Proton Beam Therapy. Bristol: IOP Publishing UK (2017). p. 1-1-1-23. doi: doi: 10.1088/ 978-0-7503-1370-4ch1

59. Devicienti S, Strigari L, D’Andrea M, Benassi M, Dimiccoli V, Portaluri M. Patient Positioning in the Proton Radiotherapy Era. J Exp Clin Cancer Res (2010) 29(1):47. doi: 10.1186/1756-9966-29-47

60. Goitein M. Trials and Tribulations in Charged Particle Radiotherapy. Radiother Oncol (2010) 95(1):23-31. doi: 10.1016/j.radonc.2009.06.012

Conflict of Interest: The authors declare that the research was conducted in the absence of any commercial or financial relationships that could be construed as a potential conflict of interest.

Copyright (C) 2021 Luo, Ali, Liu, Wang, Liu, Jin, Zhou and Liu. This is an open-access article distributed under the terms of the Creative Commons Attribution License (CC BY). The use, distribution or reproduction in other forums is permitted, provided the original author(s) and the copyright owner(s) are credited and that the original publication in this journal is cited, in accordance with accepted academic practice. No use, distribution or reproduction is permitted which does not comply with these terms. 